\title{
A Study of the Functional uses of Textual Pragmatic Markers by Native Speakers and English-medium Instruction Learners
}

\begin{abstract}
This study aims at describing and comparing the distribution of pragmatic marker (PM) use by English as a Foreign Language (EFL) speakers and English native speakers (NSs). To do this, the effect of increased contact with English, via English-medium instruction (EMI), on the use of textual PMs in learner's oral communication was explored. A functional-pragmatic approach was taken to the analysis of PMs. Textual PMs were examined due to the high frequency of these markers in the EMI setting. Participants were second-year $(\mathrm{N}=23)$, and third-year $(\mathrm{N}=18)$ business undergraduates, and a NS control group $(\mathrm{N}=10)$. Data were collected through two oral tasks. Results indicate that the groups used PMs for causal, contrast and sequential functions at similar frequencies, and that the NSs used PMs significantly more often for continuation and elaboration functions and significantly less opening and closing functions compared to the EMI groups. The results suggest that EMI might facilitate the acquisition of some functions of PMs such as the use of causal, contrast, sequential and topic shift/digression markers whereas other PMs, such as elaboration markers, may take longer to acquire. Participation in a variety of contexts and explicit instruction might aid a more balanced use of textual PMs.
\end{abstract}

Keywords: Pragmatic Markers, Textual Markers, English-Medium Instruction, Second Language Acquisition.

\section{Introduction}

Pragmatic markers (PMs) are lexical items such as: so, then, you know, and ok that are used by speakers in order to signpost their discourse for both their own as well as for their interlocutor's benefit. It is through the use of PMs that a speaker indicates how a hearer should interpret a message. Some of the functions of PMs include: aiding fluency, contributing to structure, cohesion and intelligibility, fulfilling interpersonal, 
textual, pragmatic and metapragmatic functions (Barón \& Celaya, 2010; Halliday \& Hasan, 1976). PMs tend to be used at high frequencies, especially in oral speech, and which are often employed on a somewhat unconscious level (Maschler, 1994). Research to date has taken into consideration the acquisition and use of PMs by both native speakers (NSs) and non-native speakers (NNSs). Research on NSs shows that PM use is largely unconscious, and makes up a large portion of NS speech. Additionally, research shows that NS use of PMs can vary greatly from speaker to speaker involving factors such as age, gender, socio-economic status, and geographic region (Andersen, 2001; Schiffrin, 1987). However, research on learners shows that PMs are used more sparingly and often at lower frequencies and variety, as well as at different distributions than NSs (Neary-Sundquist, 2014; Wei, 2011).

The present study takes place at a trilingual university in Catalonia, where degrees are offered through English-medium instruction (EMI), a practice which has been steadily increasing across Europe and the world over recent decades. EMI is described as a context in which English is used as the medium of instruction by and for NNSs of English in countries where English is not an official language (Hellekjær \& Hellekjær, 2015; Wachter \& Maiworm, 2014). Research in this field has steadily increased, as stakeholders demand to know whether the content learned via EMI is the same as it would be via first language (L1) instruction (see Dafouz, Camacho \& Urquia, 2014), as well as what the linguistic outcomes of such a learning context are (see c; Ritcher, 2017). So far research points towards comparable content learning but little measurable linguistic improvements (Ament \& Pérez, 2015; Lei \& Hu, 2014).

The focus of the present study is to compare the different functional uses of textual PMs between NSs and two types of EMI learners (full and semi ${ }^{1}$ ). First of all, we aim at reporting and identifying the distribution of use, as well as which functional categories of PMs are used more frequently than others. Secondly, we compare the use of PMs between the NSs and the two groups of EMI learners. The aim is to shed light on the outcomes participation in an EMI context can have on pragmatics, specifically the use of textual PMs.

1 Full referring to a full immersion where all classes are offered though English and semi referring to a semi immersion where some classes are in English and some are in the L1 


\section{A Functional-Pragmatic Approach to Pragmatic Markers}

To date much of the research on PMs has taken a structural approach with an aim to identify and classify PMs into a grammatical word class² (Brinton, 1996; Fraser, 1999; Schourup, 2011). Despite a large body of research in this area, there remains disagreement as to what grammatical functions PMs carry and thus the difficulty of considering all PMs one type of word or word class. The difficulty has been attributed, at least partially, to the highly context-dependent and multifunctional nature of PMs (Fischer, 2014). However, despite their multifunctional and context dependent nature, research suggests that PMs may have certain commonalities and tendencies; for example, they seem to carry little semantic meaning (Lewis, 2006; Mosegaard Hansen, 2006). This semantic 'weakening', as it is sometimes referred to, is thought to be the result of a degrammaticalization process which contributes to their multi-functional capabilities (Brinton 1996; Waltereit, 2006). Lexical items that may be considered PMs also tend to occur proposition-initial or -final (Mosegaard Hansen, 2006; Schourup, 1999). They are also thought to be 'propositional external' which is identified as items that do not contribute to the truth conditions of an utterance (Wilson \& Sperber, 1993) and, instead, are thought to operate on different communication planes or domains (Schiffrin, 1987). Some limitations to the structural approach have been pointed out: For example, to date the approach only accounts for the behavioural tendencies of PMs, and, what is more, most characteristics identified are not exclusive to PMs, which makes the structural categorization somewhat problematic (Fischer, 2014; Pons Bordería, 2006). The recognition of the limitations of the structural approach has led to a shift in perspective away from a structural approach towards a more pragmatic and functional approach (see such studies as Buysse, 2015, 2012; Crible \& Cuenca, 2017; House, 2013; Fernández, Gates Tapia \& Lu, 2014; Wei, 2011) following some of the earlier work of researchers such as Blakemore's Relevance theory (2001).

In the functional pragmatic approach, the term PM is used as a broad term and incorporates not only the marking of coherence functions but also the communication signals regarding the interpretation that a speaker provides for the interlocutor, thus,

2 Word class from a grammatical perspective i.e. nouns, verbs, prepositions etc. 
allowing for subclasses such as discourse markers, connectors, and routines (see Aijmer \& Simon-Vandenbergen, 2006; Fraser, 1996). The present study follows this line of research, in fact, we adopt the term pragmatic marker, following Aijmer and SimonVandenbergen (2006). By considering PMs as a larger category and recognizing a variety of different pragmatic functions within, it allows for subclasses such as discourse markers, connectors, and routines (see Aijmer \& Simon-Vandenbergen, 2006; Fraser, 1996). By defining PMs in this way, a broader perspective can be taken enabling the authors to carry out a deeper analysis on a wider variety of PMs based on their different functions which is a major contribution of the present study to the study of PMs. As Blakemore (2002) suggests, there is a need for a movement away from studying specific PMs and instead for a movement towards investigating the underlying functions of PMs. The functional-pragmatic approach stems from relevance theory, in which utterance interpretation is considered to be an inferential process which includes contextual and interpersonal factors, in contrast to a process which occurs in isolation and only on the structural level (Andersen, 2001. p. 30-33; Redeker, 1990). Thus, during communication, in order to instruct a listener as to how to interpret the speaker's message or to make explicit the intended meaning of an utterance, there is a necessity for a linguistic item to carry out these functions. Under this theory, PMs are the key items that make it possible for an interlocutor to interpret and accurately identify implicit and explicit meanings (Wilson \& Sperber, 1993). In our view this provides a strong argument to analyze PMs from a functional pragmatic perspective.

\subsection{Functions of Textual Markers}

Within the functional-pragmatic theory, PMs are thought to function for either interpersonal or textual purposes (Andersen, 2001; Halliday, 2004; Hyland, 2017; Redeker, 1990; Rouchota, 1996). Textual functions are used to refer to the discourse directly, which create and maintain discourse connections, and which are then taken up by the interlocutor and facilitate smooth interpretation of the flow of discourse. The present study adopts this view and acknowledges Andersen's (2001. p. 65-66) belief that it is possible to determine the function of a PM in context as either mainly textual or mainly interpersonal via pragmatic interpretation. 
Upon an extensive review of the research carried out to date on PMs, and following (Ament, Pérez \& Barón, 2018), eight different sub-functions seem to be clearly identified within the textual function: causal markers, contrastive markers, continuation markers, elaboration markers, opening and closing markers, sequential markers, topic shift/digression markers, and summary/conclusion markers (see Table 1). These are the functions identified and used for analysis of PMs in the present study.

Table 1. Functions of Textual Markers

\begin{tabular}{l|l}
\hline Causal markers & $\begin{array}{l}\text { To show causal relationships to show consequence or } \\
\text { effect, to mark the link between two clauses, give the } \\
\text { rationale (cause) to an argument. }\end{array}$ \\
\hline Contrast markers & $\begin{array}{l}\text { To mark a contrast between two clauses or between } \\
\text { two parts of the discourse, to show a contrast from an } \\
\text { expected response or statement and the actual one. }\end{array}$ \\
\hline Continuation markers & $\begin{array}{l}\text { To show a continuation of discourse on the same topic, } \\
\text { to add additional information in order to facilitate } \\
\text { complete comprehension. }\end{array}$ \\
\hline Elaboration markers & To elaborate, reformulate or exemplify. \\
\hline Opening and closing markers & $\begin{array}{l}\text { To signal the opening and closing of discourse or mark } \\
\text { the end or beginning of a turn. }\end{array}$ \\
\hline Sequencing markers & $\begin{array}{l}\text { To show the temporal sequence between clauses or } \\
\text { between two parts of the discourse, to structure events } \\
\text { and ideas temporally. }\end{array}$ \\
\hline $\begin{array}{l}\text { Topic shift or digression } \\
\text { markers }\end{array}$ & $\begin{array}{l}\text { To signal shifts or transitions of discourse topics, to } \\
\text { mark digression from one topic to another or return to a } \\
\text { previous topic. }\end{array}$ \\
\hline $\begin{array}{l}\text { Summary or concluding } \\
\text { markers }\end{array}$ & \begin{tabular}{l} 
To indicate or preface results, summary, or conclusions. \\
\hline
\end{tabular}
\end{tabular}

Table 1. (The identification of the eight functions of textual markers) is the result of both a review of the literature and analysis of the data from the present study. Thus, both a top down and bottom up approach was taken. Causal markers are said to mark a cause, denote the effect or show the result of the relationship between two units of discourse, for example, 'because x, y' or 'x so/because y' (Hyland, 2005; Müller, 2005). 
Contrast markers such as although, but, however, whereas, and even though mark the contrast between the main arguments of each utterance (Fraser, 1999), as well as function to show disagreement or contrast to what is expected (Cuenca, 2008). Continuation markers (sometimes referred to as connectors) function to connect units of talk (Fraser, 1999; Schiffrin, 1987). Items such as and, moreover, in addition, or so permit the speaker to add more information and are thought to possibly aid in a fuller comprehension of what is being communicated (González, 2005). Elaboration markers such as for example, such as, like, I mean, and well function as reformulation markers. The elaboration function also includes example markers which are used to mark the introduction of examples which is a type of elaboration (Clark \& Fox Tree, 2002; Cuenca, 2008). Regarding opening and closing markers such as alright, now, ok, so, to conclude, and well function to open and close turns and topics of discourse (Cuenca, 2008; Fraser, 1999; Hyland, 2005). Topic shift or digression markers are used to shift topics: For example, items such as anyway, or, whatever, so, regarding, well, and then can function in this way and are used to shift the conversation either away from or back to a discourse topic (Buysse, 2012; Fung \& Carter, 2007; González, 2005; Pons Bordería \& Estellés Arguedas, 2009). Items such as then, well, next, firstly, in the end, and after are used to present a sequence of events or mark temporal value (González, 2005). Finally, summary markers are those markers which mark the introduction to a concluding or summarizing segment of discourse, for example, so, and, yeah, well, to conclude and that's all (Buysse, 2012; Müller, 2005).

\section{The Acquisition of Pragmatic Markers in the EMI Context}

Regarding the acquisition of PMs, research thus far asserts that languages rely on PMs to organize discourse, but that the frequency, variety, distribution, and overlap of PM meanings from one language to another can vary greatly (LoCastro, 2001; Zufferey \& Gygax Pascal, 2017). This variation can present challenges for learners' pragmatic and communicative development, as it can be difficult to interpret and employ PMs in a second language (L2) due to their often elusive meanings (Jucker \& Ziv, 1998) as well as the discrepancy in use and function between L1 and L2. Indeed, even after long periods of contact with the target language, advanced learners still experience difficulty 
or even have been found to plateau when it comes to pragmatic marker learning (Romero-Trillo, 2002). Another important factor related to the acquisition of PMs is the context of learning and amount and type of input and interaction a learner receives (Hellermann \& Vergun, 2007; Polat, 2011).

\subsection{The Functions of Pragmatic Markers in the EMI Context}

EMI can be characterized as a formal, academic setting, where English is used as a lingua franca. Most participants come from the same language background and use English to discuss the content of the courses (Smit \& Dafouz, 2012; Unterberger, 2012). Professors in these settings may have different levels of oral fluency in English, but despite this, it is well documented that the lecturers are knowledgeable and especially familiar with the appropriate discourse for their field of specialty (Airey, 2012). Regarding the type of language input the EMI class offers, research thus far suggests that due to the high specificity of university classrooms the language input may be a far cry from what occurs during less formal interactions. This may be even more exaggerated in terms of PMs as they are also extremely context-dependent. Research shows that classrooms tend to offer a reduced array of communication situations compared to other more natural type settings: For example, there is a limited range of social interactions, shorter and less complex discourse organization, minimal marking of opening and closing of discourse and fewer discourse and politeness markers (Lörscher, 1986). Furthermore, it has been noted that non-native English-speaking professors may use a smaller variety of PMs in their lectures than native English speakers (Zare \& Keivanloo-Shahrestanaki, 2017). In addition to that, researchers have noted that non-native lecturers are less likely to use interpersonal stories and anecdotes, and tend to stick to content as much as possible (Kuteeva \& Airey, 2014). This speech pattern may lead to a lower degree of interpersonal marker use ${ }^{3}$ compared to textual ones. This discrepancy between the frequencies of the two types of markers is further compounded by the fact that textual markers are already used at higher frequencies compared to interpersonal markers simply due to the more formal academic setting (Zare \& Keivanloo-Shahrestanaki, 2017). For example, Crible, Degand, and

3 Interpersonal markers are used to express social functions and convey both the speaker's relation to a proposition and his or her conception of the hearer's relation to it (Andersen, 2001). 
Gilquin (2017) reported that French teachers produced lower scores of PMs in formal and scripted speech compared to phone calls and conversations. Therefore, it seems that the educational context provides a smaller variety and lower frequency of PMs in general and furthermore, of the markers that do occur, there seems to be a high frequency of textual markers and a lower frequency of interpersonal markers.

\subsection{The Role of Pragmatic Markers in Comprehension}

Speakers use PMs to construct and manage coherence (Meierkord, 2007), which makes them key elements in comprehension. Despite not being instructed explicitly on the use of PMs in EMI classrooms, there is evidence that learners pay attention to and rely on PMs for correct interpretation. For example, research has shown that the use of PMs in lectures has positive effects on comprehension (Fox Tree \& Schrock, 1999). Specifically, Östman (1995) found that the use of well, ok, anyway, oh and other PMs have significant positive effects on spoken discourse comprehension. This research has been complemented by other findings which demonstrate that listeners rely on PMs during academic lectures in order to interpret the stream of discourse. For example, Flowerdew and Tauroza (1995) played a video of the same lecture to two different groups of NNSs; in one, all PMs had been removed, and the other was left in its original form. The authors found that those who watched the lecture with intact PMs understood significantly more than those who watched the lecture with the PMs removed. These findings were replicated in Jung's (2003) study who found that those students who listened to lectures with PMs performed better on post-tests than those who listened to the lecture without PMs. These results were found to be true not only for oral comprehension but also for written comprehension. For example, Reza, Tavangar, and Tavakoli (2010) reported that learners were better able to understand texts which contained PMs than those without. The aforementioned studies provide evidence that learners attend to PMs during language processing. However, there are some alternative arguments, for example, Liu (2016) suggested that due to the low degree of lexical meaning that PMs carry, learners might simply skip over unknown PMs in the input without processing them. In addition to this, there may be other non-linguistic factors that interact with lecture comprehension, for example, a lack of familiarity with the lecture format and the overall structure of the distribution of the information given in 
a lecture, as suggested by Zare and Keivanloo-Shahrestanaki (2017). Thus, most research to date demonstrates that PMs play a key role in comprehension, and that it is highly likely that learners carefully attend to and process PMs in order to aid them in correct interpretation. The studies reviewed in the preceding paragraphs provide an argument to believe that participation in EMI might have a positive effect on the usage of the types and variety of PMs that learners acquire as a result of participation in such contexts.

\subsection{Factors Affecting the Acquisition of Pragmatic Markers}

Turning to context first, Fung and Carter (2007) compared Hong Kong adolescents from a traditional formal-instruction classroom setting to British NSs of the same age and measured their usage of PMs in a role play. They found that the NSs used PMs for a wider variety of pragmatic functions that the NNSs did. It was furthermore noted that learners tended to produce larger quantities of textual markers and lower frequencies of interpersonal ones. In line with this study, other studies report an over or underuse of PMs compared to NSs. For example, Liu (2016) studied two groups of Chinese L1 students living and studying in the US: a high- and low-socialized group, which were determined by the time spent socializing and interacting in natural settings in English. She found that the more socialized group used PMs at a higher rate than the less socialized group, and more importantly, that their distribution was more native-like, which was attributed to their increased contact with NSs. She concluded that it is not the rate of PMs that contributes to fluency but a native-like distribution. Regarding studies carried out in the EMI context, mixed results have been reported. For example, Ament \& Barón (2018) compared EMI and non-EMI learners and found that EMI learners produced more PMs than non-EMI learners. The results also showed that EMI learners signposted more through the use of structural PMs, while non-EMI used more referential PMs. In another study, Ament et al. (2018) compared the effects of EMI over 2 academic years. They reported that both EMI and semi-EMI ${ }^{4}$ learners experienced an increase in frequency and variety of PM use. However, only the EMI group experienced an increase in the use of textual markers, and neither group experienced any difference

4 Semi-EMI learners have just one or two courses taught in English in contrast to EMI learners who have their entire degree taught in English. 
with respect to interpersonal PMs. The authors suggest that the outcomes were due to the context of learning and that the EMI context may be more favorable for the learning of textual compared to interpersonal markers. Other researchers report opposite findings: for example, in a corpus study comparing Japanese and Turkish English as a foreign language (EFL) learners to NSs Babanglu (2014) analyzed essays and found that the learners tended to use interpersonal PMs that were usually used in oral communication erroneously in their writings. Additionally, they noted that the NSs produced the fewest PMs in their essays. The author concluded that factors such as register confusion, L1 transfer, or lack of or over instruction in class may be the cause of the different patterns of use of PMs on part of the learners. Considering other studies accounting for L1 transfer, results show that learners use markers at very low frequencies when they do not have a corresponding marker in their L1. For example, Liu (2013) found that Chinese learners of English transferred meanings and frequencies of use of markers such as yeah and I think, which had equivalents in Chinese, but very infrequent use of markers such as like, you know and I mean which do not have an equivalent in Chinese. Buysse (2015) also found in his comparison of Dutch, French, Spanish and Chinese learners that according to their production of the marker well, all learners performed similarly, producing more instances of well than NSs, with the exception of the Chinese participants, who seemed to not have a corresponding marker in their L1.

A handful of studies have investigated the role of explicit instruction on the acquisition of PMs. Findings show that learners are better able to mark their discourse in written texts after receiving instruction on PM use compared to those that did not receive such instruction (Cheng \& Steffensen, 1996). In line with this, Li (2015) reported that by raising learners' pragmatic awareness and providing learners with explicit instruction on PM use learning was facilitated, and more PMs were used. In sum, research on the acquisition of PMs shows that learners use PMs at different frequencies, varieties, and distribution when compared to NSs. However, this variation is not always clear or predictable due to a number of factors such as the context of learning, L1, language proficiency and explicit instruction. Thus, further research is needed in order to determine more clearly the effects of context on PM learning. The 
aim of this study is to report on the different distribution of uses of PMs between NS and NNSs and to identify the effects of EMI on the acquisition and use of PMs. Thus, the research questions proposed are the following:

1. Do second-year EMI learners, third-year EMI learners and NSs use PMs differently concerning the distribution of textual PM use?

2. If there are any differences between the groups, which functions of textual markers are used differently?

\section{Methodology}

\subsection{Design and Participants}

The participants were 48 students, 20 were male and 28 were female. There were 38 participants enrolled in an International Business and Economics degree at a university in Catalonia, 21 were second-year students and made up the experimental group 'immersion year 2' (henceforth IM2), and 17 were third-year students who made up the experimental group 'immersion year 3' (henceforth IM3). The control group was made up of 10 NSs of English enrolled in undergraduate and Masters Programs at the same university.

Results from the language background questionnaire revealed that $86 \%$ of the NNS participants were Spanish/Catalan bilinguals and that these languages were also the languages of their previous education. The remaining experimental participants were from other European countries. And the control group participants were all from English speaking countries. None of the participants in the experimental groups reported studying through EMI before entering university and also reported English as their third language. The mean age of all participants was 20 .

All of the participants in the IM2 and IM3 groups were enrolled in an International Business and Economics degree which is taught completely through the English language. The degree programme consists of 425 contact hours per academic year, and data collection was conducted halfway through the academic year. The IM2 group 
had participated in 637 hours of EMI, and the IM3 had participated in 1,062 hours of EMI at data collection (see table Table 2).

Table 2. Participants, design, and hours of exposure to EMI

\begin{tabular}{llll}
\hline \hline Experimental Groups & IM2 & IM3 & NS-group \\
\hline \hline Number (Age) & $21(19)$ & $17(20)$ & $10(22)$ \\
\hline Cumulative Hours of EMI & 637 & 1062 & n/a \\
\hline First language & $16-$ Cat/Sp & $17-\mathrm{Cat} / \mathrm{Sp}$ & $10-$ Eng \\
& $5-$ Other & & \\
\hline \hline $\begin{array}{l}\text { Year of study at the time } \\
\text { of data collection }\end{array}$ & $2^{\text {nd }}$ year & $3^{\text {rd }}$ year & $4^{\text {th }}$ or $5^{\text {th }}$ year \\
\hline \hline
\end{tabular}

\subsection{Instruments}

Four instruments were used for this study: a language background questionnaire, an English proficiency test, a monologue and an interaction task. All instruments were piloted previous to the study and were found to be effective and adequate at eliciting the desired type of language (Ament \& Barón, 2018).

The language background questionnaire established participants' previous exposure to English as well as their English language learning backgrounds. The online Cambridge placement test was administered to control for proficiency. In order to ensure homogeneity, those participants who scored either over C1 or below B2 on the CEFR ${ }^{5}$ were excluded from the analysis.

Two different types of oral tasks were chosen to broaden the communicative contexts and therefore provide more opportunity for a range of PMs to naturally occur in the learner's responses. The monologue task (MON) was completed individually, participants were asked to introduce themselves to the researcher and include information regarding the languages they speak, their English language learning experience, and why they had chosen to study their degree through English. The

5 Common European frame work of reference for languages. 
interaction task (INT) required participants to engage in conversation with another participant. Participants were asked three different questions that were related to their field of study (see appendix A).

\subsection{Procedure}

Participants completed the web questionnaire and the proficiency test online. Oral tests were carried out in sound attenuated cabins. The MON task was carried out first and participants were given two minutes to record their responses. This was followed by the INT task, in which participants were asked to discuss each question also for two minutes.

\subsection{Analysis}

Audio recordings were transcribed in the $\mathrm{CHAT}^{6}$ program using $\mathrm{CLAN}^{7}$ software and coding norms (MacWhinney, 2000). Transcriptions were checked twice to ensure accuracy. The researchers controlled coding vigorously, one researcher transcribed and checked all coded data, and another researcher re-coded 25\%. The coded transcriptions were compared to ensure accuracy. An inter-rater reliability of $95 \%$ was reached. The researchers identified and tagged each PM used in the oral tasks according to which function it carried out in the context. This was done by examining the context and the discourse before and after the item occurred. The data were analyzed in this manner based on previous research (Fung \& Carter, 2007; Neary-Sundquist, 2013; Redeker, 1990; Ament et al., 2018). Below, two excerpts from the data are provided, one from each participant group, in order to illustrate the coding process.

\section{Excerpt A. IM2 Maria and Bruno discussing question two:}

Maria: well I think that the mobile technology is developing a lot throughout the years and these will be very useful for communication and also for business

6 Codes for the Human Analysis of Transcripts

7 Child Language Analysis 
because we could exchange information very fast umm what are your thoughts about it?

Coding: Well here functions to open the discourse, and functions to continue the discourse along the same topic, adding additional information within the same turn. Because was coded as a causal marker, since the speaker gives a reason for why technology is useful in business.

Bruno: well I agree with you but I disagree in the fact that it is a way of it's a good way of communicating but I don't know it's very weird to be it's like you lose ahh some communicative skills such as a face to face conversation where for instance for a businesses it is very important to see the other who you are dealing with and if you do it like a skype conference or just ahh a phone call it's like very weird don't you think that this is a problem with the with the mobile phones?

Coding: The first occurrence of well shows the beginning of the speakers turn and marks the opening of discourse, but in both instances preface a contrast. It's like shows an elaboration and precedes the provision of more detail. Such as and for instance, preface and mark the introduction of an example or elaboration and were coded as such. And shows the addition of information to the same topic within the same turn. Like marks the provision of an example, and it's like marks an elaboration of the topic.

Excerpt B. IM3 participants Carlos and Sara discussing question two:

Carlos: well so how do you feel about this kind of mobile technology?

Coding: Well and so mark the opening of the discourse topic.

Sara: well I think that smartphones ahh have taken the contract of our live and I just I don't mean just like teenage people or people from our age but I mean all the people too because I see them and they're really focused on these screens ahh doing almost everything like working or walking they have are always it always next to them I mean I think they have taken control over almost everyone. 
Coding: Well marks the opening of discourse, like marks the introduction of an example, but marks contrast between the example given and what the speaker actually intends. Because functions to introduce reasoning to the speaker's argument. Like and I mean function to mark elaboration and further exemplification on the topic.

Carlos: $\quad$ yes and a lot of people are like they are they have like daily habits they are like changing introducing their phones into them so like before you used to sit and read the newspaper and now you see everything on your screen and I don't know they are changing as well ways of payment and I don't know and now in the mobile world congress introduced an app like opening your car with it so it's like affecting our lives in a meaningful way.

Coding: The first instance of and functions to continue the discourse of the interlocutor. The first instance of like functions to reformulate what was uttered whereas the second and third instance of like function to preface examples. So functions to show a causal relationship and give reason to the speaker's argument. The two final instances of like are used to mark the introduction of an example and the elaboration of the topic. All remaining instances of and are used to mark the continuation of the same topic. Both instances of now function to mark temporality showing the contrast between the current moment and another period in time and thus are not PMs in these instances. So functions to mark the summary or conclusion of the speaker's argument. Finally, it's like is used as a reformulation marker, reformulating the main argument of the speaker.

After coding, the frequencies were calculated for each participant using CLAN. Table 3 shows the total number of occurrences of each different function from the entire data set. It also includes a list of all the PMs that were used in the data for each function and the number of times they occurred. It was found that continuation (687), elaboration (513), and causal markers (398) were used the most frequently, followed by topic 
shifter/digression markers (333), and contrast markers (341) being used moderately, and finally summary/conclusion (184), open and closing of discourse markers (182), and sequential markers (115) being used at the lowest frequency.

Table 3. Functions and examples of items from the data

\begin{tabular}{|c|c|c|}
\hline Function & Items found in the data (number of occurrences) & $\begin{array}{l}\text { Total number of } \\
\text { occurrences in } \\
\text { the data }\end{array}$ \\
\hline Causal Markers & $\begin{array}{l}\text { And (16), because (276) in order to (7), so (89), then (6), } \\
\text { therefore (4) }\end{array}$ & 398 \\
\hline Contrast Markers & $\begin{array}{l}\text { Although (7), and (2) but (287), even though (2), however } \\
\text { (5), or (1), whereas (37) }\end{array}$ & 341 \\
\hline $\begin{array}{l}\text { Continuation } \\
\text { Markers }\end{array}$ & And (678), because (1), moreover (2), so (6) & 687 \\
\hline $\begin{array}{l}\text { Elaboration } \\
\text { Markers }\end{array}$ & $\begin{array}{l}\text { For example / instance (48), I mean (127), in that / fact (5), } \\
\text { it's like (17), like (257), so (1) such as (3), that is (1), well } \\
\text { (54) }\end{array}$ & 513 \\
\hline $\begin{array}{l}\text { Opening and } \\
\text { Closing Markers }\end{array}$ & $\begin{array}{l}\text { Alright (5), let's start (1), now (1), ok (48), right (1), so (61), } \\
\text { that's it / all (4), to conclude (1), well (59), yeah (1) }\end{array}$ & 182 \\
\hline $\begin{array}{l}\text { Topic Shift or } \\
\text { Digression } \\
\text { Markers }\end{array}$ & $\begin{array}{l}\text { All that stuff (1), and all that / those / these / things / and } \\
\text { everything (23), or / or something/ or so (65), whatever } \\
\text { (13), so (5), things like that (2) according to (1), and /then / } \\
\text { how about (81), ok (1), regarding (1), but (2), so (48), then } \\
\text { (12), well (71), what about (7) }\end{array}$ & 333 \\
\hline $\begin{array}{l}\text { Sequential } \\
\text { Markers }\end{array}$ & $\begin{array}{l}\text { And (12), as (3), finally (4), first (of all) (8), firstly (2), in the } \\
\text { end (2), next (2), now (6), nowadays (1), so (1), then (72) } \\
\text { next (2) }\end{array}$ & 115 \\
\hline $\begin{array}{l}\text { Summary, } \\
\text { Conclusion } \\
\text { Markers }\end{array}$ & $\begin{array}{l}\text { And (15), at the end (1), it leads to (2), like (4), so (150), } \\
\text { well (6), yeah (6) }\end{array}$ & 184 \\
\hline
\end{tabular}

\section{Results}

An exploration of the data was carried out first and each group's total words, total PMs per 100 words, and total types of PMs per 100 words were calculated (see Table 4). It was noted that the NSs produced longer streams of talk (within the same time limit), followed by the IM3 group and that the IM2 group produced the shortest streams of talk. 
The data was further analysed and the ratio of each functional category per 100 words was calculated. Results showed the IM3 group produced the largest amount of PMs per 100 words compared to NS, and the IM2 group produced the least PMs per 100 words. Furthermore, the percentage of each different function in relation to all PMs uttered was calculated to provide data on the relative distribution of PMs per group (see Figure 1). It was found that the NS group used continuation, elaboration and causal markers at the highest frequencies. The IM3 group showed the same pattern while the IM2 group differed; the three most frequent functions they used were continuation, causal, and topic shift or digression markers. Turning to the order of markers used moderately, the NS group used topic shift or digression markers, contrast markers and summary markers which differed from the IM3 group that showed an order of contrast markers, topic shift or digression markers and opening and closing markers. The IM2 group performed much differently showing an order of frequency of elaboration markers, contrast markers and opening and closing markers. Finally, the least frequently used functions of the NS group were sequence markers and opening and closing markers. The IM3 group showed a low frequency of use of summary markers and sequence markers. And finally, regarding the IM2 group, a similar pattern to the IM3 group was found, with low frequency usage of summary markers and sequence markers.

Table 4. Distribution of PMs for each group

\begin{tabular}{lc|c|c}
\hline \hline Group & \multicolumn{1}{c}{ IM2 } & IM3 & NS \\
\hline \hline Category & Mean & Mean & Mean \\
& SD & SD & SD \\
\hline Words & 531.48 & 691.79 & 762.80 \\
& 178.16 & 161.34 & 264.00 \\
Different Types of & 3.48 & 3.11 & 2.33 \\
PMs per 100 words & 1.12 & 0.97 & 0.75 \\
PMs per 100 words & 8.23 & 9.34 & 8.52 \\
& 2.47 & 1.64 & 5.24 \\
Causal Markers per & 1.29 & 1.36 & 1.10 \\
100 words & 0.59 & 0.44 & 0.49 \\
\end{tabular}




\begin{tabular}{ll|l|l} 
Continuation Markers & 2.15 & 2.08 & 2.69 \\
per 100 words & 1.07 & 0.58 & 2.06 \\
Contrast Markers per & 1.00 & 1.08 & 0.68 \\
100 words & 0.61 & 0.05 & 0.48 \\
Elaboration Markers & 1.13 & 1.94 & 1.83 \\
per 100 words & 0.93 & 1.16 & 1.51 \\
Opening and Closing & 0.56 & 0.84 & 0.23 \\
Markers per 100 & 0.27 & 0.46 & 0.30 \\
words Mart Markers & 1.30 & 0.94 & 0.94 \\
Topic Shift & 0.45 & 0.87 \\
per 100 words & 0.08 & 1.43 & 0.47 \\
Sequence Markers & 0.25 & 0.38 & 0.39 \\
per 100 words & 0.36 & 0.68 & 0.57 \\
Summary Markers & 0.54 & 0.38 & 0.34 \\
per 100 words & 0.37 & & \\
\hline \hline
\end{tabular}

\section{$\%$ of all PMs used per function}

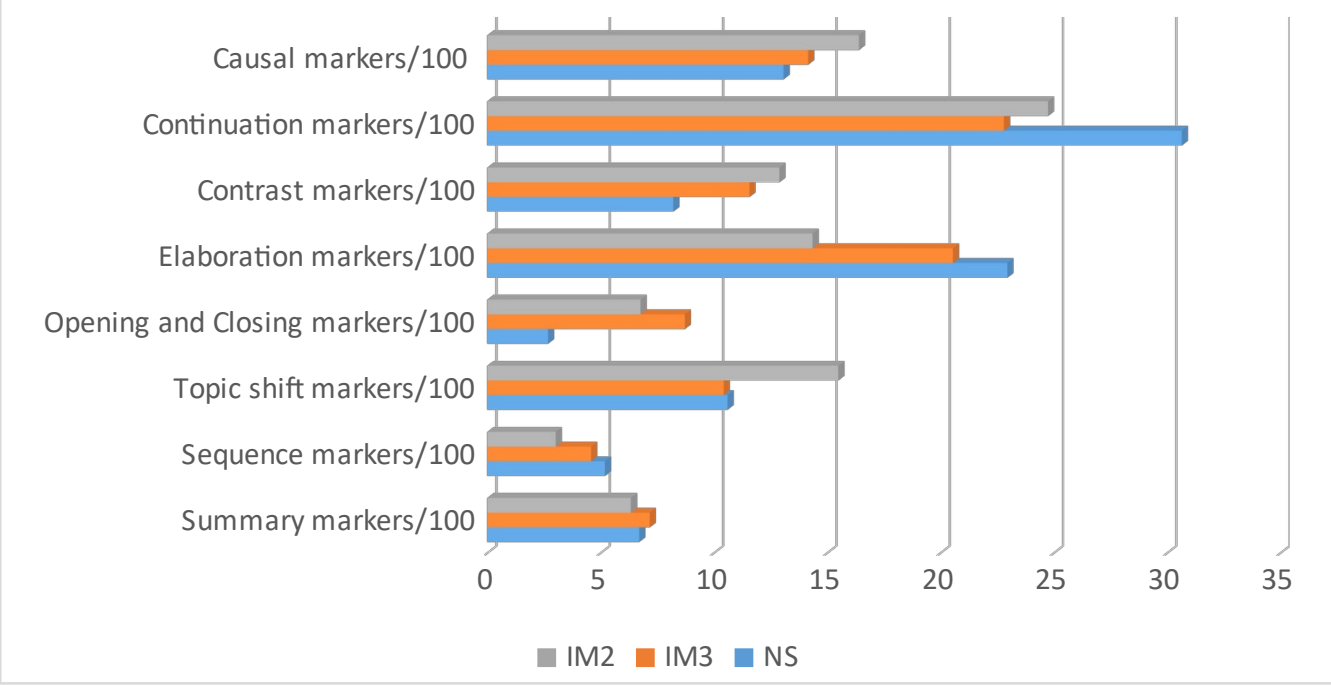

Figure 1. Percentage of PM use of each function

To answer research question 1 'Do second-year EMI learners, third-year EMI learners, and NS use PMs differently according to the distribution of textual PM use?' a 
Generalized Linear Mixed Model was carried out for the eight textual PM functions, in which the number of occurrences was set as the dependent variable (Poisson Distribution, Log Link). Group and PM, as well as their interaction, were set as fixed factors. A random intercept was set for subject (significant: $\beta=.104$. SE $=.026, p$ $<.001)$. This would detect any significant differences between groups according to the eight textual PM functions, total words, total PMs, and total types of PMs used. Results were positive, a significant fixed effect was detected for group $(F(2,432)=7.983, p$ $<.001)$. Thus the response to research question one is yes the groups used PMs at different distributions.

In order to answer question 2 'If there are any differences between the groups, for which of the eight functions are the differences significant?' the interaction between group and PM was analyzed. Fixed effects were significant $(F(1,432)=109.017, p$ $<.001)$, showing that there were differences between how the three groups used PMs. In order to identify which functions of PMs were used differently, pairwise comparisons were performed for the interaction between group and pragmatic marker with group set as the contrast field (see Table 5).

Table 5. Pairwise comparisons for the interaction between Group and PM

\begin{tabular}{|c|c|c|}
\hline \multicolumn{3}{|c|}{ Causal Markers } \\
\hline Differences Detected & $\beta$ & Adj. Sig. \\
\hline IM3 - IM2 n/s & 2.274 & 0.170 \\
\hline $\mathrm{NS}-\mathrm{IM} 2 \mathrm{n} / \mathrm{s}$ & 0.638 & 0.626 \\
\hline$N S-I M 3 n / s$ & -1.636 & 0.534 \\
\hline \multicolumn{3}{|c|}{ Continuation Markers } \\
\hline Differences Detected & $\beta$ & Adj. Sig. \\
\hline IM3 sig. more than IM2 & 4.345 & ${ }^{*} 0.020$ \\
\hline NS sig. more than IM2 & 7.046 & ${ }^{*} 0.009$ \\
\hline NS - IM3 n/s & 2.701 & 0.294 \\
\hline \multicolumn{3}{|c|}{ Contrast Markers } \\
\hline Differences Detected & $\beta$ & Adj. Sig. \\
\hline IM3 - IM2 n/s & 2.072 & 0.086 \\
\hline $\mathrm{NS}-\mathrm{IM} 2 \mathrm{n} / \mathrm{s}$ & -0.634 & 0.523 \\
\hline
\end{tabular}




\begin{tabular}{|c|c|c|}
\hline NS - IM3 n/s & -2.706 & ${ }^{+} 0.060$ \\
\hline \multicolumn{3}{|c|}{ Elaboration Markers } \\
\hline Differences Detected & $\beta$ & Adj. Sig. \\
\hline IM3 sig. more than IM2 & 7.119 & ${ }^{*} 0.000$ \\
\hline NS sig. more than IM2 & 6.955 & ${ }^{*} 0.000$ \\
\hline$N S-I M 3 n / s$ & -0.164 & 0.939 \\
\hline \multicolumn{3}{|c|}{ Opening and Closing Markers } \\
\hline Differences Detected & $\beta$ & Adj. Sig. \\
\hline IM3 sig. more than IM2 & 2.752 & ${ }^{*} 0.001$ \\
\hline NS sig. less than IM2 & -1.232 & ${ }^{*} 0.027$ \\
\hline NS sig. less than IM3 & -3.984 & $* 0.000$ \\
\hline \multicolumn{3}{|c|}{ Topic shift / Digression Markers } \\
\hline Differences Detected & $\beta$ & Adj. Sig. \\
\hline IM3 - IM2 & 0.322 & 1.000 \\
\hline NS - IM2 & -0.379 & 1.000 \\
\hline$N S-I M 3 n / s$ & -0.701 & 1.000 \\
\hline \multicolumn{3}{|c|}{ Sequence Markers } \\
\hline Differences Detected & $\bar{\beta}$ & Adj. Sig. \\
\hline IM3 - IM2 n/s & -0.130 & 0.870 \\
\hline$N S-I M 2 n / s$ & -1.265 & 0.391 \\
\hline NS - IM3 n/s & -1.136 & 0.391 \\
\hline \multicolumn{3}{|c|}{ Summary Markers } \\
\hline Differences Detected & $\beta$ & Adj. Sig. \\
\hline IM3 sig more than IM2 & 1.944 & ${ }^{*} 0.018$ \\
\hline NS - IM2 & 1.165 & 0.285 \\
\hline NS - IM3 & -0.780 & 0.399 \\
\hline \multicolumn{3}{|l|}{$\mathrm{n} / \mathrm{s}=$ not significant } \\
\hline${ }^{*}=$ Significant & & \\
\hline$+=$ near significant & & \\
\hline
\end{tabular}

Results revealed that there were no significant differences in frequency of use between any of the groups for causal markers, contrast markers, sequence markers, or topic shift/digression markers. A near significant difference was found for contrastive marker use, specifically, IM3 produced less contrastive markers than the NS group. Regarding significant differences, it was found that the IM3 group and the NS group produced 
significantly more continuation markers than the IM2 group. Elaboration markers were used significantly more frequently by the NS and IM3 group compared to the IM2 group. Markers functioning to open or close discourse were used significantly more frequently by the IM3, followed by the IM2 group and both groups significantly surpassed the NSs group. Finally, summary markers were produced significantly more frequently by the IM3 group than in the IM2 group. To summarize the group differences, when comparing IM3 to IM2, the IM3 group produced significantly more summary and continuation markers, and significantly less opening and closing markers than the IM2 group. When comparing the NS group to the IM2 group the NSs produced significantly more elaboration and continuation markers, and significantly less opening and closing markers than the IM2 group. When comparing the NS group to the IM3 group, the NSs were found to produce significantly more elaboration markers and significantly less opening and closing markers than the IM3 group.

\section{Discussion}

The present study investigated the distribution of the use of different functions of textual PMs from two different groups of EMI students and a group of NS. Eight different functions were measured. Results indicated that all groups used causal, contrast, topic shift or digression markers, and sequential markers similarly. Significant differences were found between the groups according to the functions of continuation, summary markers, opening and closing markers, and elaboration markers.

Regarding the first research question, 'do second-year EMI learners, third-year EMI learners and NSs use PMs differently concerning the distribution of textual PM use?', similarities were identified when comparing the IM3 group's distribution to that of the NS group. In fact, the IM3 group did not show any significant differences to the NS group in the distribution of use of the markers: continuation, elaboration, causal, topic shift/digression, summary and contrast markers. In contrast, the IM2 group reflected more significant differences to the NSs employing more causal, topic shift/digression markers, and opening and closing markers and fewer continuation and elaboration markers than both the NSs and the IM3 group. Thus, the response to our first research 
question is affirmative: the groups used PMs at different distributions. This discrepancy in PM distribution might be due to the amount of exposure to English, as the IM3 group had had more exposure to textual PMs than the IM2 group. The amount of exposure to $E M I$, in turn, increased the amount of processing of PMs, as was mentioned in the literature review, since some studies have claimed that EMI learners carefully process PMs during the comprehension of lectures (Jung, 2003; Reza, Tavangar \& Tavakoli, 2010). Therefore, the results found in the present study might suggest that the EMI context has a positive effect on learners' production of PMs. Similar findings were reported in Ament et al. (2018) who reported that EMI learners acquired textual PMs faster in the EMI context than a semi-EMI context and were even found to produce significantly more of these markers than NSs.

When each function of textual markers was analyzed, some similarities were found between the groups, more specifically, the three groups used causal, contrast, sequential, summary and topic shift/digression functions similarly. These results could be accounted for by a number of factors. Firstly, the functions of causal, contrast, and sequential markers are closely linked to syntax and accurate sentence structure. Thus, due to the nature of their functions, these markers might be easier to acquire, as was also suggested by both Liu (2016) and Bu (2013). Additionally, these markers are the most likely to be addressed in formal language teaching, according to Hellermann and Vergun (2007) and Vellenga (2004). It is highly likely the participants of the present study had received some explicit instruction on these markers at some point in their English language learning history, which is reflected in their competent use of them. Another factor influencing the results might be the more transparent meanings these markers hold compared to some other functions of textual markers. For example, because, but, and and have clear semantic meanings that correspond to their uses as contrast, causal and sequential markers. This feature might facilitate understanding and lead to greater ease of use compared to some of the other functions of textual markers. This finding is confirmed in other studies for example Ament \& Báron (2018), Ament et al. (2018) and Liu (2016) who found that contrast, causal and sequential markers (reference markers as they were referred to in their studies) were acquired before other markers. The final factor to consider is that the input available in EMI may be rich in 
these markers and therefore may provide learners with ample opportunity to acquire them as was suggested in some previous studies by Romero-Trillo (2002), Buysse (2015) and Fung and Carter (2007). The experimental groups of the present study were also found to perform equally concerning topic shift/digression markers. These markers function differently than the causal, contrast and sequential markers; more specifically, this function involves a certain degree of discourse management and metapragmatic thinking (Verschueren, 2000). It could be argued that the results found in the present study reflect the high level of proficiency achieved by EMI speakers, and show the positive effect of the EMI setting on learners' PM output. Similar conclusions were made by Wei (2011) who found that highly proficient learners were able to incorporate more PMs into their speech and cater to the communication task by incorporating the use of topic shifting and topic/digression marker management.

As for the second research question 'If there are any differences between the groups, which functions of textual markers are used differently?', the results reported statistically significant differences between the groups: the IM3 group and the NS group produced more continuation markers than the IM2 group. The findings showed that when the use of PMs was calculated per 100 words (Table 4.) and the distribution of PMs was calculated (Figure 1.), the IM2 group reflected a higher use than the IM3 group. This difference may reflect an over reliance of the IM2 group on continuation markers. It reflects a lesser use of a variety of different functioning PMs and an increased use of the same type (continuation) compared to the IM3 group. This finding is in line with other studies, such as the one by Ament et. al. (2018) who found that those who spent less time in EMI classes used more markers that are closely related to grammar and addressed in the L2 classroom. As Liu (2016) suggested, markers such as continuation markers are more transparent in their function and may be acquired first or with more ease than other PMs. It may be that learners begin by using these ones and that with time spent in an English speaking environment their repertoire of variety of PMs increases.

The second significant difference was that the NS group produced more elaboration markers than the IM3 group and significantly more than the IM2 group. This finding is in line with those by Liu (2013) and Fung and Carter (2007) who report a 
frequent use of elaboration markers among their NS groups. Considering the function of elaboration markers (to introduce examples, elaborate on ideas, or reformulate what has already been said) a reason for this finding could be that NSs carefully tend to the maintenance of complete and comprehensive discourse, by providing elaborations, examples, and reformulations (House, 1996). In contrast, the maintenance, management and tending to these elements of discourse structure may be more cognitively demanding for NNSs. This challenge may lead learners to avoid using elaborations, reformulations, and exemplifications, behaviour which may lead to a tendency for NNSs to express themselves in a more straightforward manner making use of connections, contrasts, continuation, causal and sequential markers. Such a pattern was noted in Buysse (2015) who suggested that learners may feel the need to make their utterances clearer than NSs do. This was echoed in Wei (2011) who found that learners communicate their ideas in a more monologic manner than NSs do.

The third significant difference noted was that both the IM2 and IM3 groups produce more opening and closing markers than NSs. We might have been inclined to suspect the opposite, as previous studies show that clearly marking speech is a sign of fluency (Shively, 2015). However, some researchers report the opposite and suggest that filling opening or closing positions with multiple PMs may actually be a sign of disfluency (Gilquin, 2008; Trenchs-Parera, 2009). Based on the present study's results, it seems that NSs mark the opening and closing and turn-taking explicitly less often than learner groups. One rationale for this finding may be that NSs do not explicitly mark their closing of turns because it is already made explicit by metalinguistic or nonlinguistic factors not considered in this study. Such factors might not be evident to learners, and they may feel unsure as to whether the correct interpretation of their utterance is ensured which might cause them to explicitly mark redundant functions. This was also noted by Müller (2005) who found that learners tended to show their lack of confidence in their linguistic skills, in the form of overuse of the discourse markers they are familiar with in contexts usually filled by other markers by NSs. Alternatively, it could be that learners use more PMs at the beginning or end of a turn because they are still cognitively processing and formulating their next communicative move as was noted by Fernández, Gates Tapia, and Lu (2014) whose learners used markers frequently as 
hesitations or thinking devices. A final suggestion is that NSs might not leave time for a speaker to complete their utterance and instead begin their turn either before or the instant the speaker stops speaking, thus, leaving little opportunity for the speaker to mark the closing of the turn.

\section{Conclusions}

The present study aimed at contributing to the study of PMs in EMI context. Some limitations of the study may be the small sample of participants, it would be more revealing to study a larger population. In addition, it would be interesting to compare the EMI groups to a non-EMI group as well as the NS group to be able to make stronger conclusions regarding the context effect of EMI. However, despite these limitations, the present study, as a first of its kind, has shed some light on the use of PMs in the EMI context. First, results show that learners in their third year of EMI approximated NS distribution of elaboration, causal, summary, contrast, sequence and topic shift and digression PMs. It may be that immersion in the EMI context facilitates the acquisition of causal, sequential, topic shifting/digression, contrast and summary markers, as the learner groups did not differ from the NSs when it came to these functions of textual markers. Secondly, an important finding of this study is that NSs were found to maintain and manage discourse more thoroughly through the incorporation of elaboration, reformulation and exemplification markers into their discourse compared to the NNSs who were found to express themselves in a more straightforward way incorporating continuation, sequencing, contrast and causal markers. Finally, in accordance with previous research, a certain degree of disfluency was noted in the NNSs groups specifically due to the overproduction of opening and closing markers. These results suggest that EMI can be effective for the acquisition of some textual PMs, while other PMs may require more time and practice, a different context, or perhaps explicit instruction to be acquired. The study suggests that participation in a variety of contexts and explicit instruction might aid a more balanced and accurate acquisition of textual PMs. 



\section{References}

Aijmer, K., \& Simon-Vandenbergen, A. M. (2006). Introduction. In K. Aijmer \& A. M. Simon-Vandenbergen (Eds.), Pragmatic Markers in Contrast. Elsevier Ltd.

Airey, J. (2012). "I don't teach English": The linguistic attitudes of physics lecturers in Sweeden. AILA Review, 1(25), 64-79.

Ament, J. R., \& Barón Parés, J. (2018). The acquisition of pragmatic markers in the English-medium instruction context. In, Pérez-Vidal, Lopéz-Serano, Ament \& Thomas-Wilhelm (eds). Learning effects: study abroad, formal instruction and international immersion classrooms. EuroSLA Studies, 1. 44-74. Berlin, Language Science Press.

Ament, J. R., \& Pérez-Vidal, C. (2015). Linguistic outcomes of English medium instruction programmes in higher education: A study on economics undergraduates at a Catalan University. Higher Learning Research Communications, 5(1), 47.

Ament, J. R., Pérez-Vidal, C. \& Barón-Parés, J. 2018. The effects of English-medium instruction on the use of textual and interpersonal pragmatic markers. Pragmatics, 28:4, 517-546.

Andersen, G. (2001). Pragmatic Markers and Sociolinguistic Variation. Philadelphia, NL: John Benjamins Publishing Company.

Babanglu, P., M. (2014). A corpus-based study on the use of pragmtic markers as speech like features in Turkish EFL learners' argumentative essays. Procedia Social and Behavioral Sciences, 136, 186-193.

Barón, J., \& Celaya, M. L. (2010). Developing pragmatic fluency in an EFL context. In EuroSLA Yearbook (pp. 38-61). John Benjamins Publishing Company.

Blakemore, D. (2002). Relevance and Linguistic Meaning: The Semantics and Pragmatics of Discourse. Cambridge: Cambridge University Press.

Brinton, L. J. (1996). Pragmatic markers in English. Berlin: Mouton de Gruyter.

$\mathrm{Bu}$, J. (2013). A study of the acquisition of discourse markers by Chinese learners of English. International Journal of English Studies JN - International Journal of English Studies, 13(1), 29-50. Retrieved from http://revistas.um.es/ijes

Buysse, L. (2012). So as a multifunctional discourse marker in native and learner speech. Journal of Pragmatics, 44(13), 1764-1782. https://doi.org/10.1016/j.pragma.2012.08.012

Buysse, L. (2015). "Well it's not very ideal ..." The pragmatic marker well in learner English. Intercultural Pragmatics, 12(1), 59-89. https://doi.org/10.1515/ip-20150003

Cheng, X., \& Steffensen, M. (1996). Metadiscourse: A technique for improving student writing. Research in the Teaching of English, 149-181.

Clark, H. H., \& Fox Tree, J. E. (2002). Using uh and um in spontaneous speaking. 
Cognition, 84(1), 73-111.

Crible, L., \& Cuenca, M. J. (2017). Discourse Markers in Speech : Characteristics and Challenges for Corpus Annotation. Dialogue and Discourse, 8(2), 149-166. https:// doi.org/10.5087/dad.2017.207

Crible, L., Degand, L., \& Gilquin, G. (2017). The clustering of discourse markers and filled pauses. A corpus-based French-English study of (dis)fluency. Languages in Contrast, 17(1), 69-95.

Cuenca, M. J. (2008). Pragmatic markers in contrast: The case of well. Journal of Pragmatics, 40(8), 1373-1391. https://doi.org/10.1016/j.pragma.2008.02.013

Dafouz, E., Camacho, M., \& Urquia, E. (2014). "Surely they can't do as well": A comparison of business students' academic performance in English-medium and Spanish-as-first-language-medium programmes. Language and Education, 28(3), 223-236. https://doi.org/10.1080/09500782.2013.808661

Fernández, J., Gates Tapia, A., \& Lu, X. (2014). Oral proficiency and pragmatic marker use in L2 spoken Spanish: The case of pues and bueno. Journal of Pragmatics, 74, 150-164. https://doi.org/10.1016/j.pragma.2014.09.005

Fischer, K. (2014). Discourse markers. In W. Bublitz, A. H. Jucker, \& K. P. Schneider (Eds.), Handbook of Pragmatics (Volume 3, Vol. 3, pp. 271-294). Berlin: De Gruyter Mouton. https://doi.org/10.1002/9781405198431.wbeal0330

Flowerdew, J., \& Tauroza, S. (1995). The effect of discourse markers on second language comprehension. Studies in Second Language Acquisition, 17, 435-458.

Fox Tree, J. E., \& Schrock, J. C. (1999). Discourse markers in spontaneous speech: Oh what a difference an oh makes. Journal of Memory and Language, 40, 280-295.

Fraser, B. (1996). Pragmatic markers. Pragmatics, 6(2), 167-190.

Fraser, B. (1999). What are discourse markers? Journal of Pragmatics, 31(7), 931-952. https://doi.org/10.1016/S0378-2166(98)00101-5

Fung, L., \& Carter, R. (2007). Discourse markers and spoken english: Native and learner use in pedagogic settings. Applied Linguistics, 28(3), 410-439. https://doi.org/10.1093/applin/amm030

Gilquin, G. (2008). Hesitation markers among EFL learners: Pragmatic deficiency or difference? In J. Romero-Trillo (Ed.), Pragmatics and Corpus Linguistics: A mutualistic entente (pp. 119-149). Berlin: Walter De Gruyter. 119-149

González, M. (2005). Pragmatic markers and discourse coherence relations in English and Catalan oral narrative. Discourse Studies, 7(1), 53-86.

Halliday, M. A. K. (2004). An Introduction to Functional Grammar. London: Edward Arnold.

Halliday, M. A. K., \& Hasan, R. (1976). Cohesion in English (2013th ed.). London and New York: Routledge. 
Harley, B., Allen, P., Cummins, J., \& Swain, M. (1990). The Development of Second Language Proficiency. Cambridge: Cambridge University Press.

Hellekjær, G. O., \& Hellekjær, A. I. (2015). Is Anglophone complacency a virtue of necessity?: The gap between the need for and supply of occupational second foreign language skills in Norwegian business and government. Scandinavian Journal of Educational Research, 59(2), 143-161. https://doi.org/10.1080/00313831.2014.904412

Hellermann, J., \& Vergun, A. (2007). Language which is not taught: The discourse marker use of beginning adult learners of English. Journal of Pragmatics, 39(1), 157-179. https://doi.org/10.1016/j.pragma.2006.04.008

House, J. (1996). Developing pragmatic fluency in English as a foreign language: Routines and metapragmatic awareness. Studies in Second Language Acquisition, 18(2), 225-252.

House, J. (2013). Developing pragmatic competence in English as a lingua franca: Using discourse markers to express (inter)subjectivity and connectivity. Journal of Pragmatics, 59, 57-67. https://doi.org/10.1016/j.pragma.2013.03.001

Hyland, K. (2005). Metadiscourse. Exploring Interaction in Writing. Oxford: Continuum.

Hyland, K. (2017). Metadiscourse: What is it and where is it going? Journal of Pragmatics, 113, 16-29.

Jucker, A. H., \& Ziv, Y. (1998). Discourse markers: Introduction. In A. H. Jucker \& Y. Ziv (Eds.), Discourse Markers Pragmatics and Beyond New Series (pp. 1-12). Amsterdam: John Benjamins Publishing Company.

Jung, E. (2003). The role of discourse signalling cues in second language listening comprehension. The Modern Language Journal, 87, 562-576.

Jung, E. H. S. (2003). The role of discourse signaling cues in second language listening comprehension. The Modern Language Journal, 87(4), 562-577. https://doi.org/10.1111/1540-4781.00208

Kuteeva, M., \& Airey, J. (2014). Disciplinary differences in the use of English in higher education: Reflections on recent language policy developments. Higher Education, 67(5), 533-549. https://doi.org/10.1007/s10734-013-9660-6

Lei, J., \& Hu, G. (2014). Is English-medium instruction effective in improving Chinese undergraduate students' English competence? IRAL - International Review of Applied Linguistics in Language Teaching, 52(2), 99-126. https://doi.org/10.1515/iral-2014-0005

Lewis, D. (2006). Discourse markers in English: a discourse pragmatic view. In K. Fischer (Ed.), Approaches to discourse particles (pp. 43-59). Amsterdam: Elsevier Ltd.

$\mathrm{Li}, \mathrm{W}$. (2015). Effective teaching in the use of pragmatic markers for Chinese EFL learners. Universal Journal of Educational Research, 3(11), 822-829. 
https://doi.org/10.13189/ujer.2015.031107

Liu, B. (2013). Effect of first language on the use of English discourse markers by L1 Chinese speakers of English. Journal of Pragmatics, 45(1), 149-172. https://doi.org/10.1016/j.pragma.2012.11.002

Liu, B. (2016). Effect of L2 exposure: From a perspective of discourse markers. Applied Linguistics Review, 7(1), 73-98. https://doi.org/10.1515/applirev-2016-0004

LoCastro, V. (2001). Individual differences in second language acquisition: Attitudes, learner subjectivity, and L2 pragmatic norms. System, 29(1), 69-89. https://doi.org/ 10.1016/S0346-251X(00)00046-4

Lörscher, W. (1986). Conversational structures in the foreign language classroom. Learning, Teaching and Communication in the Foreign Language Classroom, 1122.

MacWhinney, B. D. (2000). The CHILDES project: Tools for anlayzing talk (3rd ed.). Mahwah NJ: Lawrence Erlbaum Associates.

Maschler, Y. (1994). Metalanguaging and discourse markers in bilingual conversation. Language in Society, 23(3), 325-366. https://doi.org/10.1017/S0047404500018017

Meierkord, C. (2007). Coherence devices in the Englishes of speakers in the expanding circle. In Cross-Cultural Pragmatics and Interlanguage English (pp. 201-2019). Munich: Lincom Europa.

Mosegaard Hansen, M.-B. (2006). A dynamic polysemy approach to the lexical semantics of discourse markers (with an exemplary analysis of French toujours). In K. Fischer (Ed.), Approaches to discourse particles (pp. 21-42). Amsterdam: Elsevier Ltd.

Müller, S. (2005). Discourse Markers in natie and non-native English discourse. Amsterdam: John Benjamins Publishing Company.

Neary-Sundquist, C. (2013). Task type effects on pragmatic marker use by learners at varying proficiency levels. L2 Journal, 5(2), 1-21. Retrieved from http://escholarship.org/uc/item/9bm489h8

Neary-Sundquist, C. (2014). The use of pragmatic markers across proficiency levels in second language speech. Studies in Second Language Learning \& Teaching, 4(4), 637-663. https://doi.org/10.14746/ssllt.2014.4.4.4

Östman, J.-O. (1995). Pragmatic particles twenty years after. In Organization in Discourse (pp. 95-108). Turku: University of Turku.

Polat, B. (2011). Investigating acquisition of discourse markers through a developmental learner corpus. Journal of Pragmatics, 43(15), 3745-3756. https://doi.org/10.1016/j.pragma.2011.09.009

Pons Bordería, S. (2006). A functional approach to the study of discourse markers. In K. Fischer (Ed.), Approaches to discourse particles (pp. 77-99). Amsterdam. Elsevier. 
Pons Bordería, S., \& Estellés Arguedas, M. (2009). Expressing digression linguistically: Do digressive markers exist? Journal of Pragmatics, 41, 921-936.

Redeker, G. (1990). Ideational and pragmatic markers of discourse structure. Journal of Pragmatics, 14(3), 367-381. https://doi.org/10.1016/0378-2166(90)90095-U

Reza, A., Tavangar, R., \& Tavakoli, M. (2010). The cooperative principle in discourse communities and genres: A framework for the use of metadiscourse. Journal of Pragmatics, 42(6), 1669-1679.

Ritcher, K. (2017). Researching tertiary EMI and pronunciation. A case from Vienna. In J. Valcke \& R. Wilkinson (Eds.), Intergrating Content and Language in Higher Education; perspectives on professional practice (pp. 117-134). Frankfurt: Peter Lang.

Romero-Trillo, J. (2002). The pragmatic fossilization of discourse markers in non-native speakers of English. Journal of Pragmatics, 34(6), 769-784.

Rouchota, V. (1996). Discourse conectives: what do they link? UCL Working Papers in Linguistics, 8(199-214).

Schiffrin, D. (1987). Discourse Markers. Cambridge: Cambridge University Press.

Schourup, L. (1999). Tutorial overview: Discourse markers. Lingua, 107, 227-265.

Schourup, L. (2011). The discourse marker now: A relevance-theoretic approach. Journal of Pragmatics, 43(8), 2110-2129. https://doi.org/10.1016/j.pragma.2011.01.005

Shively, R. L. (2015). Developing interactional competence during study abroad: Listener responses in L2 Spanish. System, 48, 86-98. https://doi.org/10.1016/j.system.2014.09.007

Smit, U., \& Dafouz, E. (2012). Integrating content and language in higher education: An introduction to English-medium policies, conceptual issues and research practices across Europe. AlLA Review, 25, 1-12. https://doi.org/10.1075/aila.25.01smi

Trenchs-Parera, M. (2009). Effects of formal instruction and a stay abroad on the acquisition of native-Like oral fluency. Canadian Modern Language Review, 65(3), 365-393. https://doi.org/10.3138/cmlr.65.3.365

Unterberger, B. (2012). English-medium programmes at Austrian business faculties. A status quo survey on national trends and a case study on programme design and delivery. AILA Review, 1(25), 80-100.

Vellenga, H. (2004). Learning pragmatics from ESL \& EFL textbooks: How likely? Tes/Ej, 9(2), 1-18. Retrieved from http://tesl-ej.org/ej30/a3.html

Verschueren, J. (2000). Notes on the role of metapragmatic awareness in language use. Pragmatics, 10(4), 439-456.

Wachter, B., \& Maiworm, F. (2014). English-taught programmes in European higher education: The state of play in 2014. Bonn: Lemmens Medien $\mathrm{GmbH}$. 
Wei, M. (2011). Investigating the oral proficiency of English learners in China: A comparative study of the use of pragmatic markers. Journal of Pragmatics, 43, 3455-3472.

Wilson, D., \& Sperber, D. (1993). Linguistic form and relevance. Lingua, 90(1-2), 1-25.

Zare, J., \& Keivanloo-Shahrestanaki, Z. (2017). The languages of English academic lectures: The case of field of study in highlighting importance. Lingua, 193, 36-50.

Zufferey, S., \& Gygax, Pascal, M. (2017). Processing connectives with a complex formfunction mapping in L2: The case of French "En Effet". Frontiers in Psychology, 8, $1-11$.

Appendix A.

Questions for oral interaction:

1. First discuss the advantages and disadvantages of the following methods of communication?

Having a face to face meeting

Writing a letter

Chatting online

Giving a lecture

Having a video conference

Now you must reach an agreement which two are the LEAST effective methods of communication.

2. The mobile phone congress is currently being held in Barcelona discuss how the technology of mobile phones is changing and developing, how it may affect our lives in the future and what this means for businesses.

3. What is the most important type of technology available for businesses? why? What about personally? Which one could you never live without? Why? 